\title{
Recommendations for staff education and training for older people with mental illness in long-term aged care
}

\author{
Wendy Moyle, ${ }^{1}$ Mei Chi Hsu, ${ }^{2}$ Susan Lieff ${ }^{3}$ and Myrra Vernooij-Dassen ${ }^{4}$ \\ ${ }^{1}$ Griffith Health Institute, RCCCPI, Griffith University, Brisbane, Australia \\ ${ }^{2}$ Department of Nursing, I-Shou University, Kaohsiung, Republic of China, Taiwan \\ ${ }^{3}$ Baycrest Geriatric Health Care System, Faculty of Medicine and Department of Psychiatry, University of Toronto, Canada \\ ${ }^{4}$ Radboud University Nijmegen, Netherlands
}

ABSTRACT

Background: This paper was written as a result of the International Psychogeriatric Association Task Force on Mental Health Services in Long-Term Care. The appraisal presented here aims to (1) identify the best available evidence that underpins best practice for geriatric mental health education and training of staff working in long-term care, and (2) summarize the appraisal of the literature to provide recommendations for practice.

Methods: An initial search of databases found 138 papers related to the search strategy. Selected papers were summarized and compared against set inclusion criteria. This resulted in 17 papers suitable for review.

Results: The majority of papers focused on behavior skills training. A number of key factors were identified that determine the success of geriatric mental health education and training and recommendations are outlined.

Conclusions: Methodological weaknesses are common and highlight the need for further replication studies using strong research designs.

Key words: psychiatry, dementia, geriatric, review

\section{Introduction}

The recognition and treatment of mental illness in older people living in long-term care is challenged by the paucity of trained staff in this environment (American Geriatrics Society and American Association for Geriatric Psychiatry, 2003; Gould and Reed, 2009). The greater proportion of staff working in long-term care are unskilled care workers whose main focus is on the maintenance of residents' activities of daily living (Doyle and Ward, 1998; Beeber et al., 2010). A high proportion of professional nursing and allied support staff do not have adequate training in mental health care (Halpain et al., 1999, Hsu et al., 2005). Furthermore, there is a paucity of physicians with specialized old age psychiatry training and limited formal training in geriatrics to help guide mental health services in this environment (Halpain et al., 1999; Sivis et al., 2005). Consequently

Correspondence should be addressed to: Wendy Moyle, Griffith University, Griffith Health Institute, RCCCPI, 170 Kessels Rd, Nathan, Brisbane, Queensland 4111, Australia. Phone: +61 73735 5526; Fax: +61 737355431 Email: w.moyle@griffith.edu.au. Received 7 Dec 2009; revision requested 15 Feb 2010; revised version received 2 Aug 2010; accepted 2 Aug 2010. the care needs of older people's mental illness is expected to be managed by a limited number of professional nursing staff, general practitioner (GP) consultations, and referrals for expert opinion, such as to behavioral management specialists and old age psychiatrists. In long-term care this can result in poorly coordinated health and social services and avoidance of assessment and treatment of mental illness (Meeks and Burton, 2004).

Fortunately there is increasing evidence that demonstrates geriatric mental health training and education can help long-term care staff to understand the disease and treatment needs of residents, can improve working conditions and job satisfaction, and, subsequently, the quality of life for residents (Cassidy and Sheikh, 2002; Brodaty et al., 2003). Several countries have tried to overcome the challenges of an unskilled workforce through the development of centers and organizations to highlight the importance of geriatric mental health, and to facilitate the production of education and training materials. For example, the Canadian Coalition for Seniors' Mental Health (2006) and the Australian Dementia Training and Study Centers have produced and made freely available a vast 
array of both print and website education materials and promote their use widely. However, without a trained workforce and regular opportunities for training updates, there is the likelihood that new knowledge will not be embraced, understood or transferred into practice. It is therefore essential that the long-term care workforce is trained and educated in geriatric mental health care.

This appraisal of studies in the literature was undertaken as a result of the International Psychogeriatric Association Task Force on Mental Health Services in Long-Term Care. The appraisal outlined here aims to (1) examine the best available evidence for mental health education and training of staff working in long-term care, and (2) summarize the appraisal of literature to provide recommendations for practice.

\section{Methods}

An appraisal of selected systematic reviews and research published in English between 2003 and June 2010 was undertaken. In the absence of specific education and training guidelines, the literature search aimed to focus on review papers reporting on evidence for education and training of long-term care staff looking after older people with mental illness. Papers were included in this review if the following criteria were met:

- their main theme was education and training models with a key focus on mental illness and older people;

- they were published in a peer-reviewed journal between 2003 and June 2010; and

- they describe the evidence basis and/or recommendations for education and training in the care of older people with mental illness in long-term care.

Four major databases - PubMed, Medline, Cumulative Index of Nursing and Allied Health Literature (CINAHL), and PsychINFO - were searched using a variety of search terms and combinations including "staff education", "staff training", "staff development", "long-term care", "guidelines", "mental health" and "mental illness". A manual search of the reference lists in each identified paper helped to uncover further relevant papers. The papers were summarized and categorized, and as a means of identifying recommendations for practice they were discussed according to the available evidence for practice and evaluation.

\section{Results}

An initial search found 138 papers related to the search strategy, but the majority of these papers were excluded as they were not specific to geriatric mental health training/education programs, were not designed for long-term care, and/or were not staff specific or demonstrating best evidence. Two of the authors reviewed the identified papers for consistency of selection; where there was discrepancy this was discussed in light of the inclusion criteria until consensus was reached. These limits resulted in the identification of 17 papers which are discussed in this paper. The majority of the papers identified focused on behavior skill training programs to manage disruptive behaviors in people with dementia. Such papers tend to be directed to nursing and care staff. There was a dearth of papers that discuss medical practitioner or specialist education, although one paper described a systematic review of broad continuing professional education in relation to dementia. The papers reviewed are outlined in Tables 1 and 2 .

\section{Most effective long-term care education and training models}

The selection of the most effective education and training models for long-term care aimed at managing mental illness, and reported as systematic reviews, are presented in Table 1.

The five systematic reviews outlined in Table 1 highlight the overall importance of staff training and education and their role relating to staff satisfaction and therefore staff retention, and the potential to improve geriatric mental health care and treatment practice. The studies reported in each of the systematic reviews were predominately focused on people with early to mid-stage dementia, with an occasional training paper focused on depression.

Kuske and colleagues (2007) reported on 21 studies published over a 14 -year period that looked at in-service interventions for caregivers of people with dementia. They identified that the majority of these studies were from the U.S.A, highlighted the poor methodological quality of the majority of dementia training programs they reviewed, and suggested readers should be cautious in interpreting the study results. In particular, their paper raised concerns about the lack of evidence for transfer of knowledge from the studies into practice. However, in spite of the concerns raised, the authors also reported that when an aggregate of the results was taken into account, irrespective of the study design, the studies reviewed demonstrated at least one positive effect of training on staff.

In the papers reviewed by Kuske et al. (2007) a number of key features of education and training programs were reported which have proved to 
Table 1. The most effective long-term care education and training models

\begin{tabular}{|c|c|c|c|c|}
\hline AUTHOR/YEAR & BRIEF TITLE & METHODOLOGY & $\begin{array}{l}\text { MAIN OUTCOME } \\
\text { MEASURE }\end{array}$ & SUMMARY/CONCLUSION \\
\hline Beeber et al. 2010 & $\begin{array}{l}\text { Challenges and } \\
\text { strategies }\end{array}$ & $\begin{array}{l}\text { Systematic review } \\
(\mathrm{n}=25 \text { papers }) \text { of } \\
\text { dementia training } \\
\text { in long-term care }\end{array}$ & $\begin{array}{l}\text { Challenges effecting } \\
\text { the effectiveness } \\
\text { of training }\end{array}$ & $\begin{array}{l}\text { Need to (1) find practical ways to conduct and evaluate training, (2) involve } \\
\text { whole community in planning and design of training and information } \\
\text { needs, (3) promote use and sustainability of new practices, (4) involve } \\
\text { organizational leaders who are the key to success of programs. Eleven } \\
\text { areas to consider when providing dementia care training: involve staff, } \\
\text { residents, and families in planning; focus on the content staff and residents } \\
\text { most need; identify needs of target audience; choose training type suited } \\
\text { to audience; identification and use of resources; time available to } \\
\text { accommodate work schedules; ways to motivate staff; organizational } \\
\text { supports needed; information needed to determine effectiveness; } \\
\text { reinforcement to maintain sustainability }\end{array}$ \\
\hline Hyer et al. (2010) & $\begin{array}{l}\text { Credentialing } \\
\text { dementia } \\
\text { training }\end{array}$ & $\begin{array}{l}\text { Evaluation of } \\
\text { Florida's } \\
\text { dementia training } \\
\text { curricula } \\
(\mathrm{n}=445)\end{array}$ & $\begin{array}{l}\text { Curricula content } \\
\text { against Florida } \\
\text { legislation }\end{array}$ & $\begin{array}{l}\text { Recommends the Florida credentialing program as a model for curricula and } \\
\text { training providers to ensure educationally sound training curricula }\end{array}$ \\
\hline Rampatige et al. (2009) & $\begin{array}{l}\text { Effect of } \\
\text { continuing } \\
\text { professional } \\
\text { education }\end{array}$ & $\begin{array}{l}\text { Systematic review } \\
(\mathrm{n}=28 \text { papers }) \\
\text { on continuing } \\
\text { professional } \\
\text { education }\end{array}$ & $\begin{array}{l}\text { Improvement in } \\
\text { patient } \\
\text { management and } \\
\text { patient outcomes }\end{array}$ & $\begin{array}{l}\text { Conflicting evidence whether continuing professional education (CPE) } \\
\text { brings about change in practice and health outcomes. Recommends } \\
\text { interactive, multifaceted classes with repeated sessions which may be more } \\
\text { effective in bringing about change }\end{array}$ \\
\hline Kuske et al. (2007) & $\begin{array}{l}\text { Nursing home } \\
\text { staff training }\end{array}$ & $\begin{array}{l}\text { Systematic review } \\
\text { ( } \mathrm{n}=21 \text { papers) of } \\
\text { long-term care } \\
\text { dementia training } \\
\text { programs }\end{array}$ & $\begin{array}{l}\text { Methodological } \\
\text { quality }\end{array}$ & $\begin{array}{l}\text { Majority of research was of poor methodological quality. An aggregate of } \\
\text { results demonstrates positive effect of training on staff. Concludes that } \\
\text { there is a need for more rigorous research }\end{array}$ \\
\hline McCabe et al. (2007) & $\begin{array}{l}\text { Effectiveness } \\
\text { of a training } \\
\text { program }\end{array}$ & $\begin{array}{l}\text { Systematic review } \\
\qquad(\mathrm{n}=19 \text { papers }) \\
\text { staff training } \\
\text { programs }\end{array}$ & $\begin{array}{l}\text { Knowledge of } \\
\text { depression and } \\
\text { skill in detecting } \\
\text { depression }\end{array}$ & $\begin{array}{l}\text { Inconsistent findings. Studies indicate skills training tends to increase staff } \\
\text { knowledge and skill base and may in turn decrease behavioral problems. } \\
\text { Refresher programs needed to sustain changes and clarification needed } \\
\text { about how many and how often. Commitment from management is } \\
\text { essential. Training may lead to staff satisfaction and retention. } \\
\text { Recommends replication and development of previous studies, using } \\
\text { sound research designs }\end{array}$ \\
\hline
\end{tabular}


Table 2. Best evidence for staff education and training for dementia or depression

\begin{tabular}{|c|c|c|c|c|}
\hline AUTHOR/YEAR & BRIEF TITLE & METHODOLOGY & $\begin{array}{l}\text { MAIN OUTCOME } \\
\text { MEASURE }\end{array}$ & SUMMARY/CONCLUSION \\
\hline Fletcher et al. (2010) & $\begin{array}{l}\text { Training program in } \\
\text { residential care }\end{array}$ & $\begin{array}{l}\text { Pre-post evaluation of } \\
\text { scripted training } \\
\text { program }\end{array}$ & $\begin{array}{l}\text { Trainee satisfaction, } \\
\text { trainee rating of trainer } \\
\text { knowledge, trainer } \\
\text { rating of program } \\
\text { effectiveness and } \\
\text { trainer's perception of } \\
\text { trainee interest }\end{array}$ & $\begin{array}{l}\text { Standardized training programs viewed positively by trainees. } \\
\text { Train-the-trainer programs possible in case of standardized training } \\
\text { programs }\end{array}$ \\
\hline Mellor et al. (2010) & $\begin{array}{l}\text { Evaluation of } \\
\text { beyondblue }\end{array}$ & $\begin{array}{l}\text { Pre-post test with } \\
\text { control group }\end{array}$ & $\begin{array}{l}\text { Effects on knowledge } \\
\text { and self-efficacy }\end{array}$ & $\begin{array}{l}148 \text { staff completed beyondblue, a depression training program } \\
\text { consisting of four } 90 \text {-minute education sessions (advanced training } \\
\text { included two sessions of } 2 \text { hours' duration). } 96 \text { staff acted as } \\
\text { controls. Knowledge about depression and self-efficacy and } \\
\text { attitudes improved, and referrals for depression increased }\end{array}$ \\
\hline Mitchell et al. (2010) & $\begin{array}{l}\text { Dementia care } \\
\text { training }\end{array}$ & Evaluation & $\begin{array}{l}\text { Percentage of staff who } \\
\text { attended training and } \\
\text { characteristics related } \\
\text { to higher attendance }\end{array}$ & $\begin{array}{l}\text { Attendance increased with age, and with effective leadership and staff } \\
\text { tolerance of behavioral symptoms }\end{array}$ \\
\hline $\begin{array}{l}\text { Zimmerman et al. } \\
\quad(2010)\end{array}$ & $\begin{array}{l}\text { Outcomes of a } \\
\text { dementia care } \\
\text { training program }\end{array}$ & $\begin{array}{l}\text { Nested cohort } \\
\text { group-randomized } \\
\text { trial }\end{array}$ & Effects on knowledge & $\begin{array}{l}491 \text { direct care staff and } 171 \text { supervisors from } 16 \text { LTC settings in four } \\
\text { U.S. states participated. } 6 \text {-week training demonstrated improved } \\
\text { knowledge in } 2 \text { of } 6 \text { areas post training, and in } 1 \text { area at } 3 \text { months' } \\
\text { post training. Recommends more role clarity, training, and control } \\
\text { in the care practices taught and in the way they are practiced }\end{array}$ \\
\hline $\begin{array}{l}\text { Gould and Reed } \\
\text { (2009) }\end{array}$ & $\begin{array}{l}\text { Quality care } \\
\text { campaign }\end{array}$ & $\begin{array}{l}\text { Evaluation of } \\
\text { effectiveness of } \\
\text { training }\end{array}$ & $\begin{array}{l}\text { Effects on knowledge } \\
\text { and intention to } \\
\text { change behavior }\end{array}$ & $\begin{array}{l}\text { Learning reinforced through curriculum focus on leadership and } \\
\text { working together, use of tip cards and online learning training } \\
\text { programs }\end{array}$ \\
\hline Kuske et al. (2009) & $\begin{array}{l}\text { Training in } \\
\text { dementia care }\end{array}$ & $\begin{array}{l}\text { Interventional research, } \\
\text { evaluation of } \\
\text { effectiveness of } \\
\text { training }\end{array}$ & $\begin{array}{l}\text { Effectiveness of } \\
\text { interaction }\end{array}$ & $\begin{array}{l}\text { 3-month program ( } 5 \text { modules) in dementia care based on literature } \\
\text { findings and topics selected in focus group. Intervention carers' } \\
\text { group ( } \mathrm{n}=89 \text { ) knowledge increased significantly after training but } \\
\text { not sustained at } 6 \text {-month follow-up. Recommends ongoing support } \\
\text { and organizational and environmental changes that allow caregivers } \\
\text { to demonstrate new skills }\end{array}$ \\
\hline
\end{tabular}


McCabe et al. (2008) Effectiveness of a training program

Visser et al. (2008)

McAiney et al. (2007)

\section{Furniaux and Mitchell (2004) \\ Meeks and Burton (2004) \\ Schindel-Martin et al. (2003)}

Managing

behavioral

symptoms

Evaluation of sustained implementation of mental health

\section{Mental health training}

Nursing home staff characteristics

Teaching staff to respond
Pre-post evaluation of effectiveness of a training program to assist carers to recognize depression in community and

$$
\text { LTC }
$$

Randomized controlled trial

Evaluation Review of P.I.E.C.E.S.

Pre-post evaluation

Pre-post evaluation Review

Randomized control trial pre-test/post test
Knowledge of depression and self-efficacy in detecting depression

Behavior and quality of life of residents and staff members' attitudes

Learner confidence in recognition of mental illness and assessment design

Staff knowledge of depression and dementia

Knowledge and management of depression

Staff response to stimulated patients
52 carers (26 community and 26 LTC) completed 4 training sessions (personal care attendants) or 6 sessions (RNs and managers). Pre-post test design. Training effective in improving carers' knowledge and self-efficacy. Reduction in perceived barriers to providing care for depressed people maintained at 6-month follow-up. Recommends controlled trial research to determine whether skill leads to improved care

Long-term care staff $(n=52)$ in three facilities completed either an 8-week behavioral based program, or participated in a peer support or peer support plus education group. Significant improvement in perceived skills and knowledge of staff in education plus peer support group

Evaluation initiative with staff pre $(\mathrm{n}=1,024)$ and post $(\mathrm{n}=792)$ in $(n=439)$ nursing homes in Ontario. Positive change in staff confidence levels. Program widely accepted as standard education program for LTC staff and created a common language and common approach to managing challenging behaviors and mental health issues. Inhouse psychogeriatric resource persons and enabling and reinforcing strategies and different learning strategies ensure knowledge transfer. Key and effective strategy is to use mentors to integrate new knowledge. Importance of organizational support
Training tailored to staff $(n=78)$ identified education needs had positive effect on knowledge and confidence levels of staff

Staff $(\mathrm{n}=58)$ showed significant gains in knowledge and management of depression. Limited by lack of evaluation of practice outcomes

Skills lab evaluated staff $(n=28)$ response. Statistically significant differences in change scores for performance indicators. Staff training enhanced knowledge, improved performance and confidence. Recommends longer follow-up to assess change over time 
influence positively the effectiveness of geriatric mental health training and education in longterm care. These key features were: (1) the curriculum content should be directly planned with the audience; (2) the education should be directed towards the audience so that the learning needs of the community are met; (3) the training should be focused on the needs of the residents who are being cared for; (4) the materials must address the model of care within the facility, e.g. whether a social or medical model of care is used; and (5) the training should be provided at times that suit the audience. In addition, the authors noted the importance of organization leaders in long-term care and their role in the success of such programs. Such leaders were reported to be influential in staff attendance at training sessions, motivating staff to learn, and encouraging the transfer of new knowledge into practice. Commitment from management is therefore essential to the success of education and training programs.

Rostering of staff to attend training can be particularly challenging in long-term care where the majority of staff work part-time and there is more motivation to undertake the tasks they are employed to complete rather than training, which they may see as an impediment to completion of their work (Edwards et al., 2003). To assist with such challenges and to bring about change in practice, Kuske and colleagues (2007) report that training programs should offer interactive and multifaceted classes that have repeated sessions, and they should be supplemented by short and regular reinforcement sessions.

McCabe et al. (2007) provide an account of a systematic review of the effectiveness of training programs for behavioral problems among older people with dementia. They report on 19 studies, with and without control groups, and deduce that staff education and training may be of benefit, in particular in improving staff self worth and job satisfaction, and in reducing the potential for challenging behaviors displayed by residents. They conclude that there is a need for regular refresher training programs and support, and also report on the need for commitment from management as being essential for program success. Indeed, longterm care organizations that value and support staff education and training are considered to be assistive in the effectiveness of such programs (Kaasalainen, 2002).

McCabe et al. (2007) acknowledge the inconsistent results in the papers they reviewed and advocate the need for replication and development of previous studies using strong research designs, such as randomized controlled trials, rather than further evaluation of single studies.
The limitations of continuing education need to be considered when designing geriatric mental health education and training programs. A review of continuing professional education on health care outcomes ( $\mathrm{n}=28$ papers) by Rampatige et al. (2009) concluded that interactive, multifaceted interventions, or interventions with repeated inputs, appear to be more effective in bringing about positive change. They also report on the conflicting evidence available as to whether continuing education actually changes practice, and therefore these authors recommend the need for further research in this area.

Hyer and colleagues (2010) undertook a review and evaluation of self-selected dementia curricula in Florida and compared each curriculum to Florida's legislation for dementia training curricula. Of the 445 curricula submitted they identified 401 (92\%) as not being sound. A number of the curricula did not pass an initial review because they were considered to be of poor quality. Hyer et al. (2010) concluded that an important component of effective training programs was legislation that dictates curricula content, and programs requiring approval of curricula according to such legislation. Hyer et al. (2010) suggest that such approval helps to ensure that content is up to date and is adjusted for new learning technologies. Many of the curricula they reviewed contained out-dated information or inaccurate information. The issue of education and training evaluation is discussed further in the following section.

\section{Evaluation of long-term care staff training programs aimed at mental illness}

Although training and education is common in long-term care and can include classroom and on-the-job training, there is limited evidence of regular and rigorous evaluation of the effectiveness of such programs (Beeber et al., 2010). This review explored the literature in relation to evaluation and effectiveness and identified the most successful programs to train and educate long-term care staff in geriatric mental illness. These programs are presented in Table 2.

Once again, the majority of these programs focused on dementia and depression training/education. The 12 training programs selected demonstrated positive change in staff knowledge and/or competency, and utilized strong research designs such as randomized controlled trials (Schindel-Martin et al., 2003; Visser et al., 2008; Zimmerman et al., 2010), which are considered to be the gold standard for determining intervention effectiveness, or pre-and post-test design with a control group (Mellor et al., 2010). Where a control 
group was not used (McCabe et al., 2008) the study had other strengths such as large participant numbers.

The key features of the selected programs include using recognized and tested programs to encourage change. Programs explored included the Australian beyondblue depression training program (Mellor et al., 2010) and the U.S. dementia care training program (Zimmerman et al., 2010). Such programs were deemed to be successful as the audience was involved in the direction of the training curriculum (Zimmerman et al., 2010), the program was tested during its development with various groups (Mellor et al., 2010), and the programs were tailored to the needs of the audience for which it was intended (Furniaux and Mitchell, 2004). Where the training content included a focus on leadership this was found to reinforce learning and resulted in positive change, in particular to intentions to change behavior and encourage staff to work collaboratively (Gould and Reed, 2009). In addition, staff learning was also reinforced by activities such as tip cards and on-line learning. However, without organizational leadership and support, learning was not maintained (Visser et al., 2008; Kuske et al., 2009).

In spite of the emphasis in the systematic reviews on different styles of training, didactic training on depression and behavior was also found significantly to improve participants' knowledge of depression and management (Meeks and Burton, 2004). The mean age of participants in this study was 43.80 years $(\mathrm{SD}=12.04)$, and this may help to explain the findings. In an examination of the effectiveness of a dementia training program, Mitchell and colleagues (2010) found that attendance increased with age and they hypothesized that older workers may feel more responsible towards education and training. Mitchell et al. (2010) also found that programs were more successful where there were organizational policies that were accepting of resident behaviors, and effective leadership that was supportive of training. They recommend that organizations support training and education and suggest motivational systems, such as public recognition of training, as a positive means to help achieve this.

A study by McAiney and colleagues (2007) explored an innovative education program aimed at managing mental health problems in longterm care. The "Putting the P.I.E.C.E.S. (Physical, Intellectual, Emotional, Capabilities, Environment, Social) Together" program was a province-wide initiative in Canada. Adult learning concepts and ongoing evaluation shaped the program, with the main focus of the program being the appointment of an inhouse Psychogeriatric Resource Person (PRP).
A pre-post questionnaire with a large population $(\mathrm{n}=1,024$ (pre) and 792 (post)) assessed learner confidence. In addition, a survey of 439 longterm care facilities looked at sustainability of the program. The researchers found there were significant increases following engagement in the program in staff ability to recognize and understand challenging behaviors and mental health problems. A key success of the program was the ongoing sustainability achieved through the PRP. Where facilities built the PRP role into staff job descriptions and staff were given dedicated time to do the role, then the initiative was rated as more successful. The training of more than one staff member as a PRP ensured support for staff and coverage during staff absence.

Given the challenges of recruitment and retention in long-term care (Edwards et al., 2003), this study offers promise as a strategy to enhance not only staff learning but also sustainability by building a critical mass of trained staff through the use of a PRP. Furthermore, such a program appears to be cost effective, although an economic evaluation would help to ensure this, and it offers the opportunity to improve resident care and to reduce behavioral disturbance. Although not measured in the McAiney et al. (2007) study, it is assumed that a reduction in resident challenging behaviors may have a positive influence on staff job satisfaction.

\section{Discussion and recommendations}

The majority of the studies reviewed in this paper focus on behavioral management skills rather than on the mental health needs of an older population living in long-term care. While not wanting to dispel the importance of dementia education and training, this review, alongside the increase in the number of older people with mental illness in long-term care, suggests there is also a need for attention to the broader mental health education and training of staff who provide care and treatment for older people living in these environments.

Long-term care staff are regularly challenged by disruptive behaviors as a result of the increase in the number of residents with dementia (Watson et al., 2003). This may account for the majority of the literature reviewed which describes staff training programs predominately in behavioral management terms. The recent focus on dementia in countries such as the U.S.A. and Australia may also have influenced the increased number of dementia training papers in this review. However, unless other types of mental illness are considered there is a possibility that such conditions will be neglected in long-term care. 
Our review focused only on papers that we selected as determining best practice in geriatric mental health education and training in longterm care. The studies demonstrate support for education and training in a number of conditions. While curriculum designers and trainers can influence the success of the programs, it is vital that the organizational leaders are supportive of the training - without this support it will be difficult for programs to be effective in changing behavior and translating knowledge into practice.

Even though the importance of education and training are extolled (Nolan et al., 2008; Doyle, 2009), there is controversy as to whether they encourage positive change in practice. Cerveo (1985) identified four factors that may influence whether education and training result in participant behavior change and client care improvement, the quality of educational input, individual motivation, the nature, complexity and acceptability of the proposed change initiative, and the receptivity of the care environment and its organizational context. Alongside learner characteristics such as learner motivation, the type or design of education and training plays a key role in the success or failure of the program. In addition, education programs need to consider factors that reinforce new knowledge, transfer knowledge into practice and sustain education (Stolee et al., 2009). The four factors identified nearly three decades ago by Cerveo (1985) as being able to influence the degree to which education and training will bring about change in participant behavior and improvement in client care are still relevant to best practice in geriatric mental health education and training in long-term care. In the absence of guidelines in this area, a number of recommendations have been gleaned from this review of the literature. These recommendations are framed around the four factors identified by Cerveo; the references cited are those from the review that support the recommendations.

\section{Recommendations}

\section{QUALITY OF THE EDUCATIONAL INPUT}

a. Involve community/intended audience in planning and design of training and information needs (Beeber et al. 2010; Zimmerman et al. 2010).

b. Use a credentialing program to ensure educationally sound training curricula (Hyer et al. 2010).

c. Standardize training programs and trainers (Fletcher et al., 2010).

d. Use well validated education/training programs when available (Mellor et al., 2010).

\section{INDIVIDUAL MOTIVATION}

a. Content should be focused on information that meets the needs of staff and residents (Furniaux and Mitchell, 2004 Beeber et al., 2010).

b. Training type should be suited to the audience (Beeber et al., 2010).

c. Use interactive, multifaceted classes with repeated sessions as well as refresher sessions (McCabe et al., 2007; Gould and Reed, 2009; Rampatige et al., 2009; Hyer et al., 2010).

3. NATURE, COMPLEXITY AND ACCEPTABILITY OF THE PROPOSED CHANGE INITIATIVE

a. Promote use and sustainability of new education and training practices (Kuske et al., 2009; Beeber et al., 2010).

b. Encourage positive tolerance of behavioral symptoms by staff (Mitchell et al., 2010).

c. Use positive reinforcement to maintain sustainability (Beeber et al., 2010).

d. Promote role clarity in training and reinforce learning through curriculum focus on leadership and working together (Gould and Reed, 2009; Zimmerman et al., 2010).

e. Use mentors to integrate new knowledge and sustainability within the workplace (McAiney et al., 2007).

4. RECEPTIVITY OF THE CARE ENVIRONMENT AND ITS ORGANIZATIONAL CONTEXT

a. Commitment and support from the facility for education/training is essential (Beeber et al., 2010; Kuske et al., 2009; McCabe et al., 2007).

b. Effective and supportive leadership within the facility is essential for success (Mitchell et al., 2010).

\section{Limitations}

This paper did not set out to explore every paper related to long-term care education and training nor all papers related to long-term geriatric mental health education and training. The authors selected systematic reviews and research published in English between 2000 and June 2010 according to a number of criteria and following an in-depth analysis by two of the authors. The recommendations therefore must be read in light of the literature selected for this review.

\section{Conclusions}

The majority of the studies reviewed in this paper focus on behavioral management skills rather than on mental health needs of an older population living in long-term care. This review indicates that there is also a need for attention to be placed on broader mental health education and on the training needs of staff who provide care and treatment for older people living in these environments. The recommendations may serve as indicators for best practice in both the development and sustainability 
of long-term care geriatric education and training programs. Further research is required in this area using more rigorous study designs. In addition, a consistent measure of success of such programs is also required. While skills training may increase knowledge, the literature demonstrates that ongoing training is required to sustain changes.

\section{Conflict of interest}

None.

\section{Descriptions of authors' roles}

WM undertook the literature search and wrote the first draft of the paper. WM and $\mathrm{M}-\mathrm{CH}$ analyzed papers, and $\mathrm{M}-\mathrm{CH}, \mathrm{SL}, \mathrm{MV}-\mathrm{D}$ contributed to the writing of the paper.

\section{Acknowledgment}

The authors wish to acknowledge the role of David Conn and John Snowdon in forming the International Psychogeriatric Association Task Force on Mental Health Services in LongTerm Care and encouraging the writing of these recommendations.

\section{References}

American Geriatrics Society and American Association for Geriatric Psychiatry. (2003). Consensus statement on improving the quality of mental health care in U.S. nursing homes: management of depression and behavioral symptoms associated with dementia. Fournal of the American Geriatrics Society, 51, 1287-1298.

Aylward, S., Stolee, P., Keat, N. and Van Johncox, M. A. (2003). Effectiveness of continuing education in long-term care: A literature review. The Gerontologist, 43, 259-271.

Australian Institute of Health and Welfare (AIHW) (2007). Australia's Health 2007 (No. 10). Canberra: Commonwealth of Australia.

Beeber, A. S., Zimmerman, S., Fletcher, S., Mitchell, C. M. and Gould, E. (2010). Challenges and strategies for implementing and evaluating dementia care staff training in long-term care settings. Alzheimer's Care Today, 11, 17-39.

Brodaty, H., Draper, B. and Low, L. F. (2003). Nursing home staff attitudes towards residents with dementia: strain and satisfaction with work. Fournal of Advanced Nursing, 44, 583-590.

Canadian Coalition for Seniors' Mental Health (CCSMH) (2006). National Guidelines for Seniors' Mental Health: The Assessment and Treatment of Mental Health Issues in Long-Term Care Homes. Toronto: CCSMH. Available at: http://www.ccsmh.ca/en/natlGuidelines/initiative.cfm; last accessed 22 May 2010.
Cassidy, E. L. and Sheikh, J. I. (2002). Preintervention assessment of disruptive behavior problems: a focus on staff needs. Aging and Mental Health, 6, 166-171.

Cerveo, R. M. (1985). Continuing professional education and behavioural change: a model for research and evaluation. Fournal of Continuing Education in Nursing, 16, 85-88.

Doyle, C. (2009). International perspectives on dementia education, training and knowledge transfer. International Psychogeriatrics, 21, S1-S2.

Doyle, C. and Ward, S. (1998). Education and training in residential dementia care in Australia: needs, provision and directions. Australian and New Zealand fournal of Public Health, 22, 589-597.

Edwards, H., Chapman, H., Forster, E., Gaskill, D., Morrison, P. and Saunders, F. (2003). Challenges associated with implementing an education program in a residential aged care setting, Australian Health Review, 26, 107-115.

Fletcher, S. et al. (2010). Implementation fidelity of a standardized dementia care training program across multiple trainers and settings. Alzheimer's Care Today, 11, 51-60.

Furniaux, J. and Mitchell, T. (2004). Mental health training helps care home staff. Mental Health Nursing, 24, 4-8.

Gould, E. and Reed, P. (2009). Alzheimer's Association quality care campaign and professional training initiatives: improving hands-on care for people with dementia in the U.S.A. International Psychogeriatrics, 21, S25-S33.

Halpain, M. C., Harris, M. J., McClure, F. S. and Jeste, D. V. (1999). Training in geriatric mental health: needs and strategies. Psychiatric Services, 50, 1205-1208.

Health Survey for England (2000). The General Health of Older People and their Use of Health Services. London: The Stationery Office.

Hsu, M. C., Moyle, W., Creedy, D. and Venturato, L. (2005). An investigation of aged care mental health knowledge of Queensland aged care nurses. International Fournal of Mental Health Nursing, 14, 16-23.

Hyer, K., Molinari, V., Kaplan, M. and Jones, S. (2010). Credentialing dementia training: the Florida experience. International Psychogeriatrics, epublished ahead of print, doi:10.1017/S1041610210000426.

Kaasalainen, S. (2002). Staff development and long-term care of patients with dementia. fournal of Gerontological Nursing, 28, 39-46.

Kuske, B., Hanns, S., Luck, T., Angermeyer, M. C., Behrens, J. and Riedel-Heller, S. G. (2007). Nursing home staff training in dementia care: a systematic review of evaluated programs. International Psychogeriatrics, 19, 818-841.

Kuske, B. et al. (2009). Training in dementia care: a cluster-randomised controlled trial of a training program for nursing staff in Germany. International Psychogeriatrics, 21, 295-308.

McAiney, C. A. et al. (2007). Evaluation of the sustained implementation of a mental health learning initiative in long-term care. International Psychogeriatrics, 19, 842-858.

McCabe, M., Davidson, T. and George, K. (2007). Effectiveness of staff training programs for behavioural problems among older people with dementia. Aging and Mental Health, 11, 505-519. 
McCabe, M. P., Russo, S., Mellor, D., Davison, T. E. and George, K. (2008). Effectiveness of a training program for carers to recognize depression among older people. International fournal of Geriatric Psychiatry, 23, 1290-1296.

Meeks, S. and Burton, E. G. (2004). Nursing home staff characteristics and knowledge gain from a didactic workshop on depression and behaviour management. Gerontology and Geriatrics Education, 25, 57-66.

Mellor, D., Kiehne, M., McCabe, M. P., Davison, T. E., Karantzas, G. and George, K. (2010). An evaluation of the beyondblue depression training program for aged care workers. International Psychogeriatrics. Epublished ahead of print, doi: 10.1017/S1041610210000153.

Mitchell, C. M., Zimmerman, S. and Beeber, A. S. (2010). Dementia care training for long-term care staff. If you provide it, will they come? Alzheimer's Care Today, 11, 40-50.

Nolan, M. et al. (2008). The role of education and training in achieving change in care homes: a literature review. fournal of Research in Nursing, 13, 411-433.

Rampatige, R., Dunt, D., Doyle, C., Day, S. and van Dort, P. (2009). The effect of continuing professional education on health care outcomes: lessons for dementia care. International Psychogeriatrics, 21, S34-S43.

Schindel-Martin, L., Morden, P., Cetinski, G., Lasky, N., McDowell, C. and Roberts, J. (2003). Teaching staff to respond effectively to cognitively impaired residents who display self-protective behaviors. American fournal of Alzheimer's Disorders and Other Dementias, 18, 273-281.

Sivis, R., McCrae, C. S. and Demir, A. (2005) Availability of mental health services for older adults: a cross-cultural comparison of the United States and Turkey. Aging and Mental Health, 9, 223-234.

Stolee, P. et al. (2009). Sustained transfer of knowledge to practice in long-term care: facilitators and barriers of a mental health learning initiative. Gerontology and Geriatrics Education, 30, 1-20.

Visser, S. M., Mccabe, M. P., Hudgson, C., Buchanan, G., Davison, T. E. and George, K. (2008). Managing behavioural symptoms of dementia: effectiveness of staff education and peer support. Aging and Mental Health, 12, 47-55.

Watson, L. C., Garrett, J. M., Sloane, P. D., Gruber-Baldini, A. L. and Zimmerman, S. (2003). Depression in assisted living: results from a four state study. American fournal of Geriatric Psychiatry, 11, 534-542.

Zimmerman, S. et al. (2010). Outcomes of a dementia care training program for staff in nursing homes and residential care/assisted living settings. Alzheimer's Care Today, 11, 83-99. 